\title{
Cover Cracking of the Reinforced Concrete due to Rebar Corrosion Induced by Chloride Penetration
}

\author{
J. C. Gálvez ${ }^{1 *}$, S. Guzman ${ }^{1}$, J. M. Sancho ${ }^{2}$ \\ ${ }^{1}$ Departamento de Ingeniería Civil-Construcción, Universidad Politécnica de Madrid, E.T.S.I. Caminos, \\ Canales y Puertos, C/Profesor Aranguren s/n 28040 - Madrid, Spain. Jaime.galvez@upm.es \\ ${ }^{2}$ E.T.S. Arquitectura. Universidad Politécnica Madrid. Av. Juan de Herrera s/n, 28040 Madrid, Spain
}

Durability of reinforced and precast concrete is not an innovative aspect in the scientific-technical world and it is concerned with in numerous codes, standards and recommendations. The reparation of the durability problems is very expensive. For example, according to the Federal Highway Administration, approximately $30 \%$ of the American bridges were either structurally deficient or functionally obsolete in 2001. [1]. Among degradations sources we can consider: corrosion (either due to carbonation or chloride ingress), freezing and thawing cycles, abrasion, thermal gradients, chemical attacks, dissolutions processes and alkali-aggregate reactions [2]. Evidently every isolated process can interact with each other increasing structural damage this way [3].

This paper is focused on the problem of the chloride-induced corrosion of the rebar in reinforced concrete, with special application to the slabs and decks of the bridges. High superficial concentrations may be usual in these structures (marine environments or de-icing salts in roadway bridges, e.g.). Like any aggressive agent such as water, gases or other dissolved ions, chloride induced deterioration is very conditioned by possibilities of transport through concrete mass.

In the case of models for the chloride induced corrosion, the common service life involves two time periods: the first is the time for chloride diffusion and the second is the time for corrosion damage. According to Monte Carlo analysis, failure probability is based on time depending on materials properties and stochastic distribution of external loads: cover depth, chloride content analysis, surface chloride concentration, apparent diffusion coefficient based on Fick's second law (because of chemical reactions taking place between the penetrating agent and concrete, see ASTM C1556-04), chloride corrosion initiation concentration (may depends on composition of concrete and environmental parameters) and time to corrosion damage [1].

This paper presents a model for the chloride diffusion in the concrete taking into account the pore structure of the concrete, the internal humidity and the temperature. The model accomplishes the concentration of the chloride, the gradient of the concentration, the temperature and the humidity. The model also models the presence of cracks in the concrete. Based on the results of chloride diffusion a corrosion rebar is assumed and the radial expansion of the corroded reinforcement simulated. The possible cracking around the rebar is modeled with an embedded cohesive model [4]. The model has been implemented in the FEAP Finite element code. The steel radial expansion is simulated by means of a temperature increase.

\section{References}

[1] T. J. Kirkpatrick, R. E. Weyers, C. M. Anderson-Cook, M. Sprinkle, Probabilistic model for the chloride-induced corrosion service life of bridge decks, Cement Concrete Res 32 (2002) 1943-1960.

[2] O. Coussy, F. J. Ulm, Elements of Durability Mechanics of Concrete Structures, in: Proc., Creep, Shrinkage and Durability Mechanics of Concrete and other Quasi-Brittle Materials, Wittmann, 2001.

[3] R. Mu, C. Miao, X. Luo, W. Sun, Interaction between loading, freeze-thaw cycles, and chloride salt attack of concrete with and without steel fiber reinforcement, Cement Concrete Res 32 (2002) 1061-1066.

[4] J. M. Sancho, J. Planas, D. A. Cendón, E. Reyes, J. C. Gálvez, An embedded crack model for finite element analysis of concrete fracture, Eng Fract Mech 74 (2007) 75-86. 